\title{
A "dimensão moral" do romance de Machado de Assis
}

Pedro Meira Monteiro

Não SERÁ de todo exagerado imagide Assis conformam um grande cenário em que as principais tendências da crítica literária brasileira, tomada amplamente, se desenrolam e se dramatizam. Como se, nos debates que hoje envolvem os nomes mais notáveis da crítica machadiana, se atualizasse muito daquela efervescência que marcou a recepção coeva da obra madura de Machado, e que se estampa tão bem nas divergências entre Sílvio Romero e José Veríssimo. Para além do juízo negativo ou positivo, ou do suposto "erro crítico" de Romero, o que estava (e talvez ainda esteja) em questão são as relações do autor com o seu tempo, e a opção por compreendê-lo a partir de elementos que apontam para o entorno social, para as especificidades "brasileiras" de sua obra, ou, diferentemente, para as suas inspirações literárias mais remotas que, tomadas isoladamente, terminariam por afastá-lo do Brasil, convertendo-o, na nossa imaginação, em um autor mais "universal".

Tais categorias (um Machado universal versus um Machado local) são evidentemente insuficientes, se não simplesmente falsas. Mas talvez valha a pena observar com mais cuidado, ou mesmo com alguma simpatia, o sentido profundo dessa contraposição tão simples, que a nossa boa consciência crítica manda relativizar, ou então recusar. Talvez aí, na tensão inaugurada por seus contemporâneos, estejam traçados muitos dos rumos que todavia hoje os estudiosos de Machado de Assis seguimos, ainda quando procuramos refutar os artifícios da dualidade.

O livro de José Luiz Passos, Machado de Assis: o romance com pessoas, vem em muito boa hora, e se instala, repleto de questões e provocações, no seio da crítica machadiana. Há o que celebrar, seja pela qualidade da escrita, seja pela novidade da abordagem, e pela maneira como ele reflete várias tendências críticas.

Não se trata, contudo, de novidade absoluta ou momentosa. O livro é antes o resultado de uma escuta paciente e demorada da voz dos grandes leitores de Machado, num diálogo muitas vezes implícito, embora frontal, com as matrizes que nos ajudam a compreendê-lo. Mas é também verdade que, ao mergulhar na constituição da "pessoa moral" no romance machadiano, José Luiz Passos está, em certo grau, dando novas formas a argumentos que estão em Augusto Meyer e, mais recentemente, em Alfredo Bosi. Argumentos que reclamam, enfim, uma atenção especial e um investimento crítico forte naquilo exatamente que tornaria Machado "nosso contemporâneo", não, aliás, por conta de alguma qualidade extraordinária que o faça pairar além de seu tempo e seu espaço, mas simplesmente pelo "tratamento que deu às motivações humanas, pela minuciosa composição de heróis que refazem suas próprias histórias na medida em que são alvo da mirada alheia" (p.24).

Sabe-se que a discussão das "máscaras" em Machado aponta, já na crítica de Meyer, mas sobretudo em Bosi, para uma 
série ilustre de fontes em que se destaca a matriz moralista: do Eclesiastes aos grandes pessimistas do século XIX, passando pelos primeiros pensadores modernos da política e da economia, e especialmente pelos moralistas franceses dos séculos XVII e XVIII. Tal discussão, que contempla o espaço muitas vezes abismal que separa o ser do parecer, e que no plano social distingue a intenção declarada da ação dos seus reais efeitos, ganha em Passos um desenvolvimento atento à formação do "juízo moral”, o que o faz empreender uma análise detalhada dos intermináveis labirintos que compõem a "pessoa" nos textos de ficção. Conquanto as fontes buscadas para explicar tal composição moral dos personagens possam ser diversas, a questão é ainda e sempre o espaço que medeia entre o que o sujeito declara e o que dissimula.

Reduzindo brutalmente seu argumento, a hipótese que fornece eixo a esse livro programadamente fragmentário (que aliás flerta com a forma de um tratado de moral) é a ideia de que os personagens machadianos possuem uma verdadeira "dimensão moral", isto é, uma densidade propriamente humana, que não se encontraria nem no andamento romântico dos romances de Alencar, nem na composição dos personagens no romance naturalista, ambos - os personagens românticos e os naturalistas - guiados quase completamente por algo que está fora deles mesmos, seja o projeto moralizador do escritor, que os torna portadores de virtudes e vícios inequívocos em diversos romances de Alencar, seja o peso do meio que inelutavelmente determina a ação do indivíduo, como no drama naturalista estampado nos romances de Aluísio Azevedo.

Tal dimensão moral, que explicaria a grande novidade de Machado de Assis na literatura brasileira e latino-americana no século XIX, abre a cortina ao problema da representação, levando o crítico a sondar e compreender os mecanismos e os debates que terão permitido a Machado construir personagens que até hoje nos parecem reais, dotados de uma autonomia e de uma graça própria, isto é, sujeitos que se movem moralmente, que aprendem diante da ação e da mirada dos outros, e que portanto podem nos surpreender, exatamente porque se alteram ao longo da narrativa, tornando-se, a rigor, diferentes do que foram; no limite, tornando-se diferentes de si mesmos. Mas o que os move estará sempre dentro, não fora do sujeito.

Há ação e há sentido da ação nos personagens machadianos, o que aliás explica a inspiração weberiana que desponta em certas passagens da análise de José Luiz Passos. Há também uma densidade crescente nesses personagens (das mulheres mais ou menos dissimuladas dos primeiros romances aos narradores pouco confiáveis dos romances posteriores), o que traz à tona o tema da memória e dos fantasmas que compõem a subjetividade, detectáveis por meio de um tom confessional cujas origens mais profundas remontam a Santo Agostinho, um autor fundamental para Machado e para Passos. Em suma, trata-se, no caso do personagem machadiano, de um sujeito cuja ação se converte em enigma, o que era um problema completamente atual: "A psicanálise, a sociologia e o romance realista e naturalista comungam da mesma fascinação pela questão que a partir daquele momento entrava em voga: como e por que as pessoas agem da maneira que agem?" (p.65).

Os desvãos que habitam o sujeito (a 
diferença entre o sujeito e ele mesmo, que se perfaz no tempo da narrativa) não poucas vezes fariam o indivíduo lançar-se a um projeto "reparador", que se expressa ora no esforço ingente dos personagens por parecerem ser o que não são, ora no esforço dos narradores por dar sentido à rede de desconfiança com que o seu olhar apanha a ação do Outro. Em ambos os casos, a máscara é ainda e sempre o elemento por meio do qual Machado opera a sua ficção. Os seus personagens ganhariam teor e densidade exatamente por conta desse desencontro que se entranha no eu, e que Passos compreende por meio de uma mirada abrangente, que contempla tanto a literatura europeia contemporânea a Machado (literatura que encontraria nele o seu tradutor, algumas vezes literalmente) quanto os modelos brasileiros (e portugueses) que ele refuta ou modifica.

O espectro da análise é amplo, e se justifica num livro cheio de idas e vindas, de diálogos entrecruzados que não cabem todos, nem mesmo simplesmente listados, numa resenha. Mas convém, de toda forma, lembrar que a questão das máscaras e da economia dramática que converte os personagens em pessoas verossímeis leva o crítico a privilegiar o teatro na formação de um senso machadiano do drama. Não é tanto o teatro do próprio Machado que estará então em pauta, mas sim a crítica teatral e a influência que sofreu da intensa atividade dramatúrgica no Rio de Janeiro do século XIX, em especial o Otelo que João Caetano levaria ao palco a partir da leitura de Jean-François Ducis, adicionando-lhe, entretanto, um "tenso gestual romântico" (p.197) que devolvia a Shakespeare algo que a leitura neoclássica francesa havia atenuado. Teria sido sobretudo a partir dos embates en- tre o teatro romântico de João Caetano e a dramaturgia realista do Teatro Ginásio Dramático que Machado "educou-se esteticamente" (p.200).

A centralidade de Shakespeare para a obra machadiana, e a fixação pelo Otelo, explicar-se-ia em grande parte pela importância da "malícia" de Iago, que é também central para a análise de Passos, que não apenas dialoga com uma larga tradição da crítica, como amplia significativamente a compreensão do que parece fundamental no autor do Dom Casmurro: o "tratamento da faculdade do engano". Esse é um momento crucial em Machado de Assis: o romance com pessoas, já que Shakespeare é sua mais forte referência, o que aliás explica o utilíssimo Apêndice que traz uma "Cronologia da presença de Shakespeare em Machado de Assis" (p.253-84).

Num livro que em certo sentido recusa um único centro, é sem dúvida arriscado buscar um ponto nervoso em que se expressaria o principal de sua tese. Arrisco, no entanto, supor que é mesmo Shakespeare quem, da perspectiva de José Luiz Passos, fornece a Machado sua educação literária, mediada, é claro, pela "recepção do drama europeu no Rio de Janeiro", o que abre à crítica um verdadeiro universo de referências que atravessam o século XIX:

É nesse contexto que, entre 1855 e 1878, referências a Shakespeare estiveram presentes ao longo da reflexão machadiana sobre a arte: inicialmente como aliado romântico a Victor Hugo na batalha contra as versões neoclássicas das tragédias shakespearianas de Ducis; em seguida como aliado realista na rejeição do gestual, das motivações e do vocabulário romântico de José de Alencar e de João Caetano; finalmen- 
te, Shakespeare surge como sinônimo do potencial humanista da arte no ataque de Machado ao Naturalismo de Émile Zola, realizado em sua resenha de O Primo Basílio de Eça de Queirós. (p.204)

O contexto a que Passos se refere diz respeito às teses que culminariam na defesa de uma "análise de paixões e caracteres", no célebre "Notícia da atual literatura brasileira: instinto de nacionalidade", de 1873.

Uma contribuição a meu ver fundamental é ainda o estudo da maneira como aquele exercício de adensamento dos personagens, que marcaria a novidade e a modernidade precoce de Machado, estaria já presente, como num laboratório, nos romances da chamada "primeira fase". Assim, a crítica de Passos colabora decisivamente em questionar a forma muitas vezes mecânica por que se conclui que os romances anteriores às Memórias póstumas de Brás Cubas seriam menores, ainda recendendo a um romantismo que o autor finalmente bateria em sua fase "madura". Se é verdade que o par amoroso e a formação da família fornecem ainda lenha para a fogueira da primeira ficção machadiana, não menos verdade seria que

mesmo dentro desse contexto, os seus protagonistas são acometidos por uma falta original, por uma sensação de culpa, ou por um desejo espúrio que os distancia pouco a pouco dos personagens românticos. Eles procuram com insistência superar um estado primordial de humilhação por meio de uma trajetória calculada e ascendente socialmente. Assim, a formação da nova família em Machado está vinculada à capacidade particular que seus protagonistas possuem de dissimular, mascarando suas motivações e origens. (p.53)

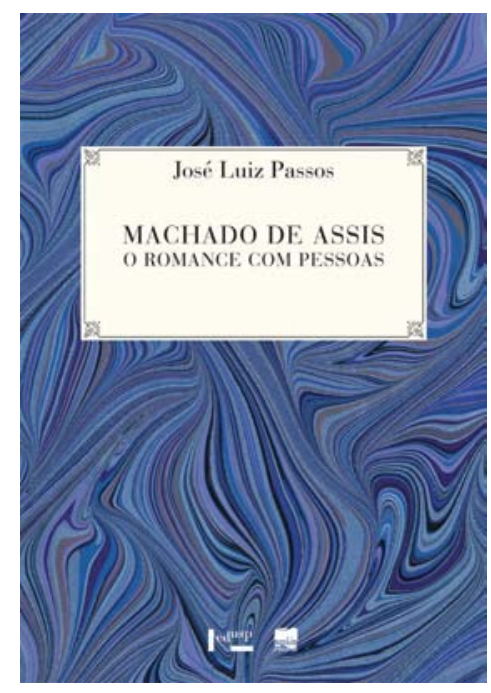

PASSOS, José Luiz. Machado de Assis: o romance com pessoas. São Paulo: Edusp, Nankin, 2007.

Essa percepção aguda, entretanto, tem talvez um preço, que é a manutenção de Alencar como o Outro de Machado de Assis, essa espécie de sparring partner que desempenha o papel incômodo de ser, na nossa imaginação, tudo aquilo que Machado viria a superar. O estudo de José Luiz Passos não chega a tal extremo de desqualificação de Alencar, mas tampouco se afasta muito desse ponto. Suponho haver aí terreno fértil para debate. De toda forma, permanece a tese forte da diferença machadiana, que leva o crítico, num momento feliz de síntese, a concluir que o "romantismo havia criado um corpo para o Brasil. Machado the daria uma consciência" (p.129).

Há certamente muito mais a encontrar nesse livro, seja lendo-o em sequência, seja abrindo-o ao acaso, já que as hipóteses de leitura vão e vêm, amarradas em diversas frentes, com as quais o leitor sempre apanhará uma nova nuança, um detalhe esclarecedor ou uma provocação inesperada. Destaco ainda a percepção 
das fontes da melancolia machadiana, que culmina na mirada do conselheiro Aires: um olhar fundo cuja desconfiança em relação ao progresso leva o crítico a encontrar uma fina linhagem em que se aproximam Euclides e Nabuco, e em que se encontra ainda o interesse pelo Império em Oliveira Lima e Rio Branco.

Machado de Assis: o romance com pessoas é movido por um desejo de demonstração que pode por vezes causar a impressão de que a retomada sucessiva de hipóteses e análises seria simples repetição no corpo do livro. Mas não é esse o caso. A "repetição" cumpre aí outra função, já que as retomadas são sempre em níveis diversos, e os problemas, mesmo quando se repõem, organizam-se de acordo com uma mirada preocupada com múltiplos aspectos. Nas palavras do crítico,

a meu ver, o que faz falta ao nosso entendimento do romance machadiano são paráfrases mais finas, descrições que sejam capazes de apanhar a sutileza dos motivos desses personagens. Eivados que são de enleio e duplas intenções, saber com clareza quem eles são, como se formaram e do que se compõem não é tarefa vã. E para esclarecer essa arte da insinuação, nossa entrada inconspícua na modernidade literária, o meu modo será o do exemplo e o da indução. (p.47)

Por essas e outras razões, o livro de José Luiz Passos passa a ser indispensável no quadro da crítica machadiana.

Pedro Meira Monteiro é professor de Literatura Brasileira em Princeton University, nos Estados Unidos.

@ - pmeira@princeton.edu 